\title{
The Impact of Social Change Communication: Lessons Learned from Decades of Media Outreach
}

William N. Ryerson and Negussie Teffera

In East Los Angeles, Jessie Martinez is in love with the football star Jacob Aguilar. But Jacob is dating the prom queen, Vanessa de la Cruz, and Jessie does not think she has a chance. However, Vanessa leaves the prom to have sex in the back of a car with another student, and Jacob finds out. Eventually, he finds Jessie is much nicer to be with, and they become a couple. But Jessie is trying to stay on the dance team and has sex with the dance coach, Christian Vasquez, after he gives her "private lessons" in his apartment. Pretty soon, Jessie discovers she is pregnant. Thus begins the first season of the US TV show, East Los High, created by Population Media Center (PMC) and broadcast on Hulu for five seasons. With the help of her hip aunt, Paulina Martinez, Jessie ends up seeing a Planned Parenthood counselor, and by the end of season 1 , she decides to

W. N. Ryerson $(\bowtie)$

Population Media Center, South Burlington, VT, USA

e-mail: ryerson@populationmedia.org

Negussie Teffera

Former Resident Representative of PMC in Ethiopia, Addis Ababa, Ethiopia

(C) The Author(s) 2021

L. B. Frank, P. Falzone (eds.), Entertainment-Education Behind the

Scenes, https://doi.org/10.1007/978-3-030-63614-2_3 
terminate the pregnancy and the planned marriage with Jacob in order to go to college. Vanessa ends up being HIV positive and becomes a safe sex counselor for students.

Teens do not go home from school to read health messages. PMC created the show in 2013 to reach youth in the US, especially Latinx youth, who have the highest rates of teen pregnancy and parenthood of any group in the US. Through PMC's then West Coast Representative, Sonny Fox, PMC President Bill Ryerson met with Nely Galan, the former President of Telemundo, to seek her advice on how to develop such a show. She connected PMC with Carlos Portugal, who at our first meeting became Head Writer and Director of what became East Los High. He gathered a team of writers from the Latinx community, and we trained them in the "Sabido methodology of entertainment-education" and how it could be adapted and applied to an online program with transmedia elements. Virginia Carter, former Head of Drama for producer Norman Lear, took part in the training and then became a volunteer reviewer of scripts throughout the production of the show. PMC's Vice President for Communications and Programs, Katie Elmore, moved from PMC's Vermont headquarters to Los Angeles to oversee the show and, after season 1, formed Wise Entertainment, which continued to produce the show for PMC for the remaining seasons. East Los High was PMC's first application of the Sabido methodology in the US, which followed many applications in the developing world, where it originated.

\section{ENTERTAINMENT-EDUCATION \\ AND THe SABido Methodology}

The Sabido methodology is based on the pioneering work of Miguel Sabido of Mexico (Sabido, 2004). The methodology is unique in that it is founded on various psychological principles related to behavior adoption and behavior modification. Sabido was Vice President for Research of Televisa, the largest TV network in Mexico, from the 1960s through 1998. During the 1970s he pioneered a new social-content communication model, using entertainment telenovelas to promote literacy, family planning, and other social development goals. In the early 1970s, he interviewed Stanford University psychologist Albert Bandura and incorporated 
Bandura's Social Learning Theory into the design of characters. Sabido also read the writings of other theoreticians on behavioral modification. During 1976-77, the first novela to promote family planning, named Acompáname ("Accompany Me"), showed in dramatic terms over the course of the nine-month serial the personal benefits of planning one's family, by focusing on the issue of family harmony. This occurred a few years after contraception was legalized in Mexico, and it led to a dramatic increase in the use of family planning, as outlined below.

The results of Acompáname, as reported by the Mexican government's national population council, included the fact that inquiries for family planning information increased from zero to an average of 500 a month. Many of those making inquiries said they did so after watching the telenovela. More than 2000 women registered as voluntary workers in the national program of family planning. This was an idea suggested and role modeled in Acompáñame. Contraceptive sales increased 23 percent in one year, compared to a 7 percent increase in the preceding year. More than 560,000 women visited family planning clinics, an increase of 33 percent (compared to a l percent decrease in the previous year; Sabido, 1982).

Sabido produced four additional family planning telenovelas in the 1970s and 1980s. They were Vamos Juntos ("We Go Together"), Caminemos ("Let's Walk"), Nosotros las Mujeres ("We the Women"), and Por Amor ("For Love"). During the decade when these Mexican programs were on the air, the country underwent a 34 percent decline in its population growth rate. As a result, in May 1986, the United Nations Population Prize was presented to Mexico as the foremost population success story in the world.

Thomas Donnelly (personal communication), then with USAID in Mexico, wrote, "Throughout Mexico, wherever one travels, when people are asked where they heard about family planning, or what made them decide to practice family planning, the response is universally attributed to one of the soap operas that Televisa has done. The Televisa family planning soap operas have made the single most powerful contribution to the Mexican population success story."

The effects of East Los High were also notable. It became the most popular program among Latinx viewers of Hulu and was in the top five in ratings during its five-year run. It received five Emmy nominations. In the first month of broadcast, more than 27,000 viewers linked from the show's website to a Planned Parenthood widget to get information on reproductive health services. Planned Parenthood and many other reproductive 
health service providers were partners for the initiative. Among viewers, 60 percent said they referred East Los High's resources to a friend (Wang \& Singhal, 2016).

Can media outreach create lasting change? For certain it can be an uphill climb. At the end of a long day of work, whether sitting in an office, standing in a factory, or laboring on a farm, many individuals want to simply relax and engage in some form of passive entertainment. That desire is where the Population Media Center (PMC) has seen success. In fact, the work of PMC started in the developing world-first in Ethiopia, Africa's second most populous country-and only later arrived in the US.

\section{PMC and the Whole Society Strategy}

In Ethiopia, as in East Los High, PMC applied what it terms the Whole Society Strategy, in order to have maximum effects on the behavioral issues addressed. The Whole Society Strategy approach to positive behavior change encompasses multiple forms of media and entertainment, focusing on delivering educational messages in the form of entertainment as opposed to straightforward behavior change messages. In Ethiopia, PMC developed serialized dramas, supplemented by talk shows, call-in programs, print materials, and other formats. In Hollywood, this strategy is often called transmedia storytelling. East Los High utilized multiple websites with various supportive information related to the content of the serial drama, many with links to partner NGOs. Some of these sites included entertainment elements, like backgrounds on various characters, while others contained more educational content related to the issues being addressed in the show. In Ethiopia, the media mix was different, based on our analysis of media consumption patterns in that country. Over time, the media mix in each country is changing, with increased use of social media and television, so it is important to keep the media analysis up to date (Negussie, 2017).

PMC combines a society's desire for entertainment with educational content designed for the public good. In the book, EducationEntertainment and Social Change: History, Research, and Practice, we provided details of what is involved in creating entertainment-education (Ryerson \& Negussie, 2004). Dr. Negussie Teffera, the former director of the National Office of Population in Ethiopia, worked as the Resident Representative of PMC-Ethiopia from 2000 to 2019 to develop a series of soap opera-like radio programs, each designed to positively influence 
public health behaviors. Using similar program strategies, PMC has worked in over 50 countries and has reached over 500 million people with its programs. PMC's programs in each country address the high-priority issues of specific relevance to each country. These issues may include educating people about the benefits of small families, encouraging the use of effective family planning methods, elevating the status of women and girls, promoting gender equality, promoting girls' education, stopping violence against women and girls, including child marriage, preventing exploitation of children, encouraging avoidance of HIV infections, promoting child nutrition, and promoting positive environmental behaviors. The overriding mission of PMC is to bring about a sustainable planet with equal rights for all. In many countries, its programs are the top-rated shows on the air. Characters on these serialized dramas become topics of so-called water cooler discussions. Some, over time, evolve into role models for the audience on social, health, environmental, and human rights issues.

In Ethiopia, PMC created serial dramas that were broadcast on radio, distributed on cassette tape, and available over the Internet. These were often supported by numerous talk shows, stage plays, capacity-building workshops for leadership groups, and other communication activities (such as discussion groups to spread messages throughout the society), ultimately reaching a huge audience and effecting substantial changes in how citizens think and conduct themselves with respect to the list of societal issues mentioned above.

Some of the widely successful programs addressing HIV/AIDS and family planning included the radio series Yeken Knight ("Looking Over One's Daily Life"), which was performed in the Amharic language over 257 episodes; and Dhimbibba ("Getting the Best Out of Life"), broadcast over 140 episodes in the Oromiffa language. A serial story, Maleda ("Dawn") was recorded on cassette tapes and distributed to truck drivers. A stage play, Yesak Jember ("Laughter at Dusk"), was performed for six months in 14 cities (Negussie, 2008).

PMC's serial dramas are culturally and linguistically sensitive to people's needs and appeal to audiences by portraying real-life situations. They help create positive attitudes and encourage the adoption of behaviors displayed by characters that gradually evolve into positive role models. Unlike documentaries or single-episode dramas, serial dramas allow the audience to form bonds with the characters over time as the characters evolve in their thinking and behavior at a gradual and believable pace in 
response to problems that have been well-defined in the storyline (Barker \& Sabido, 2005; Nariman, 1993).

Storylines have proven to be compelling. For example, in one story of Yeken Kignit, listeners learn that plans for a wedding and reception are moving forward, invitations have been distributed, and a shop owner promises to deliver food for several hundred guests. But Zinabu, the truck driver charged with the delivery, is a day late. A known drug dealer has accompanied him on his trip, and no one can find him. A phone call hints that there has been some terrible tragedy on the highway. These and other story lines keep audiences coming back week after week, creating a forum to deliver important messages benefiting the whole society.

In Ethiopia and other countries, the programs have led to changes in norms such as a tripling of self-reported family planning use among married women who were listening to the first program and a quadrupling of HIV testing among male listeners-all in a two-year period. Since almost half of Ethiopia's population was listening to each program, the impacts have been measurable on a national basis both by PMC and by the independent Demographic and Health Survey. The post-broadcast survey of about 3000 people following Yeken Kignit demonstrated the impact of Demlew's storyline. Demlew married Anguach, who is a wonderful partner for him, but Demlew's mother does not like his choice of brides. So, she conspires with the neighbor to have the neighbor get Demlew drunk and seduce him, with the hope of breaking up the marriage (remember, this is a soap opera). When Demlew sobers up, he comes back to Anguach and begs for forgiveness. She takes him back, but after some months, he becomes sick, and they get him tested for HIV. He finds out that his one night with the neighbor resulted in his becoming HIV positive. Anguach then gets tested and finds out she is negative. Going forward, the couple takes steps to protect Anguach from infection, by using condoms (Negussie, 2008).

The post-broadcast quantitative survey found that male listeners of Yeken Kignit reported seeking an HIV test at four times the rate of nonlisteners (Negussie, 2008). Female listeners reported seeking a test at three times the rate of non-listeners (Negussie, 2008). And after controlling the data for variables that might have influenced the outcome, like income, education, and place of residence, a listener was two and a half times as likely to have been tested as a non-listener. Additionally, the postbroadcast nationwide survey also showed that 46 percent of the population (age 15-59) reported listening to the Amharic program, and 25 
percent reported listening to the Oromiffa program. At 48 clinics across the country, 14,400 client interviews conducted during the broadcast found that 63 percent of new clients seeking reproductive health services reported that they were listening to one of the PMC serial dramas. Importantly, 18 percent of new clients named one of PMC's programs by name as the primary motivating factor for seeking services. Of new clients who cited radio programs as a motivation for seeking services, 96 percent said that they were motivated by one of PMC's programs. During the program, the PMC office in Addis Ababa received over 25,000 letters of appreciation from loyal listeners (Negussie, 2008).

One of these letters, from the Oromia region, thanked PMC for addressing the issue of marriage by abduction. The woman who wrote the letter stated that one of her daughters had been abducted on her way to school at age 14 and ended up married as a result. She said she was afraid to send her twin 12-year-old girls to school for fear that the same thing would happen to them. When PMC's program addressed the country's law against marriage by abduction through the character Wubalem, the mother wrote that the villagers, many of whom listened to the show, came together to discuss the situation. The villagers agreed to enforce the law which they had not known existed and now, she wrote, it was safe to send their daughters to school (Negussie, 2017).

PMC has also conducted training for Ethiopian journalists in how to effectively cover reproductive health issues. An outgrowth of this work is the publication of 14 books with selected short stories, fiction and nonfiction. Many of the stories have been read over radio stations where they have been listened to by more than 40 million people across Ethiopia. The books are now considered essential reading in most Ethiopian universities for those studying Ethiopian literature and short story writing. All books have been distributed to the libraries of Ethiopian government agencies, UN organizations, professional associations, schools, and other organizations throughout the country.

The success of PMC's Whole Society Strategy can be explained under the umbrella of three broad categories: A wide "buy-in" to the approach by governments, grassroots level community organizations, and multiple nongovernmental organizations; an approach to create content that is cost-effective and based on an independently proven approach; and an implementation and measurement system that is flexible and adjusts to the specific audiences. 


\section{Wide Buy-In to the Concept}

A society such as Ethiopia is an important location to implement a Whole Society Strategy. Women's health in Ethiopia is undermined by a combination of social, cultural, and economic factors that determine their longstanding low status in society. The country is one of the poorest in the world, with a low life expectancy (66 years), and shockingly high illiteracy rates. Changing any aspect of the culture in Ethiopia would take agreement from the highest levels of government to the most remote villagers, but equally important, grassroots advocacy organizations.

As we previously wrote (Ryerson \& Negussie, 2004), implementing a nationwide entertainment-education program and associated materials (brochures, books, formal and informal discussion events, to name a few) requires the hearts and minds of all key players in a country. This includes governmental and nongovernmental organizations. In PMC's experience, the participants have included the Ethiopian National Office of Population, the Ministry of Health, the HIV/AIDS Prevention and Control Office's Secretariat, the United Nations Population Fund, the World Health Organization, UNICEF, UNAIDS, the Family Guidance Association of Ethiopia (the national affiliate of Planned Parenthood), and the Organization for Social Services for AIDS. Additional partners have included the David and Lucile Packard Foundation, the Hughes Memorial Foundation, the Flora L. Thornton Foundation, CARE-Ethiopia, UN Women, USAID, US Centers for Disease Control and Prevention, the Norwegian Embassy, the World Bank, Save the Children, the Ethiopian Public Health Association, Brown University, Jimma University, Bayer Corporation, private business leaders, and 35 individual contributors.

Involvement goes far beyond participants like those just cited. In preparation for its media outreach, PMC worked with more than 3000 individuals representing religious leaders, youth and women's association leaders, journalists and media practitioners, writers, and health program coordinators. All were given training on communication skills, advocacy, and social mobilization approaches to address specific issues and meet the Whole Society Strategy goals. All parties agreed on the goals, which included reducing family size, increasing the ideal age for marriage and childbearing, growing the use of contraceptives and helping the population understand contraceptives' relative safety, and accepting women as part of the workforce (Negussie, 2017). 
Script and story line development for the various programs was conducted in partnership with the Ministry of Health and the national broadcast service. In addition, a large collection of NGOs, government ministries, and UN agencies were involved as part of the program, as were technical advisory committees for the production and writing teams. A team of technical advisors was tasked with reviewing every script before production of each episode to make sure the information being provided was accurate and reflected the cultural realities of the listening audience. The program advisory committee worked to make sure the clinical services that were portrayed in the storyline would be available when the program generated demand. They also participated in independent surveys of new clients. Many writers spent extensive time various in communities, embedding themselves to better understand the audiences.

\section{Leveraging Available Resources and Using Proven Methodologies}

Deep-seated, ingrained behavior does not change overnight. The Whole Society Strategy involves ongoing collaboration with all of the aforementioned government and NGO organizations, conducting extensive research to identify audience segments, media formats, and a commitment to involving all key parties in the development of solutions. Along with obtaining a broad-based buy-in, PMC leveraged local resources to produce content. The Drama Department of the University of Addis Ababa participated in learning the methodology of social-content serial dramas during a PMC workshop conducted by Miguel Sabido and then began teaching it to students. The leading demographer in the country, Dr. Assefa Hailemariam, oversaw the research to measure the effects of the program and worked in collaboration with American sociologist Dr. Earl Babbie in the design of the research instruments.

The writing team was chosen from the top writers in the country, both from the National Theatre and the University of Addis Ababa. The writing and production team were given five weeks of training in the methodology of entertainment-education, including personal training by Miguel Sabido, Virginia Carter, former Head of Drama for Norman Lear in Hollywood, and Tom Kazungu of Kenya, the first radio professional to use the Sabido methodology in Africa (Negussie, 2017).

The training included presentation of the results of extensive qualitative formative research into the cultural realities in the country, knowledge and attitudes regarding the issues to be presented, the availability of 
reproductive health services in the country, the official policies of the country with regard to each of the issues to be addressed, and the methodology to be used in addressing the issues in the context of a long-running serialized drama.

A key factor in the success of the programs in Ethiopia is following a proven methodology. In addition, PMC leveraged extensive use of formative research, sophisticated audience research methods, pretesting and use of multiple media to target the message, plus monitoring and evaluation.

\section{Being Flexible to Adjust Formats, Platforms, and Content}

In each country, PMC analyzes media consumption patterns and languages spoken across the country. Ethiopia has 84 languages. The national language of Amharic is the one most widely spoken. The second most common language is Oromiffa. As a result, these two languages were chosen for PMC's first two programs. The media analysis showed Radio Ethiopia is the only broadcaster with nationwide coverage, so Radio Ethiopia was selected for reaching the largest possible audience (Negussie, 2017). However, PMC chose to use its own studio to produce the program to avoid control of its content that might have happened if the program were produced at Radio Ethiopia. Having our own studio also ensured that it was available whenever we needed it, and the quality of a private studio was superior. We engaged our own studio technicians, producers, scriptwriters, and actors in order to ensure that the program met PMCs' standards for quality. We contracted with the National Service of Radio Ethiopia for the airtime to ensure it was broadcast during peak listening hours. Because the project was being done in collaboration with the Ministry of Health, PMC was able to secure airtime at a discounted rate.

PMC wrote and produced each episode 15 weeks in advance of the broadcast date, ensuring we never missed an episode. By writing and producing the program during broadcast, we were able to make modifications based on audience feedback. We sought feedback via on-air quizzes, focus group discussions among listeners, and encouraging letters and electronic communications from listeners.

Following PMC's first two programs, we continued producing and broadcasting another seven programs as of this writing. Each of them has a significantly measurable impact. For example, the production and distribution of a serial drama on audiocassettes called Maleda ("Dawn") was designed for play by truck drivers at high risk for HIV along the Addis 
Ababa-Djibouti highway corridor. The evaluation of the drama showed major changes in self-reported behavior by those who listened to the program. PMC later broadcast a modified version on Radio Ethiopia. Among other findings, the evaluation showed that listeners were 4.3 times more likely than non-listeners to know where to go for HIV counseling and testing services. Listeners to another program (Menta Menged or "Crossroads") were 1.8 times more likely to take measures to protect themselves from HIV infection than non-listeners (Negussie, 2017).

Johns Hopkins University's Population Report (Cho, 2008) showed that the foundations for the success of the Ethiopian program were PMC's following of a systematic process of program planning, thorough analysis of Ethiopia's socio-cultural situation, use of a strategic design for establishing the communication channel and objectives, PMC's use of theory and evidence in its strategy development, pretesting to ensure relevance and sensitivity, effective implementation and monitoring for improving storylines, and rigorous evaluation to find out improved reproductive health behaviors.

The objectives of PMCs programs are mainly to create awareness and to equip the participants with knowledge about social issues of national concern. The capacity-building awareness creation program is largely concerned with the reinforcement of and changes in community norms. It also seeks to empower audiences and subsequently community members through their health actions. The capacity-building programs also seek to provide opportunities for participants to share experiences on those issues and reach consensus on how to resolve problems. All the capacity-building components have been successful in producing trained professionals and change agents drawn from relevant government and nongovernment organizations.

The outpouring of emotion in Ethiopia, in response to PMC's work, has been overwhelming. From all over the country-and beyond the borders of Ethiopia-over 40,000 letters have poured into PMC's office in Addis Ababa. Ethiopia's news media have run about 100 stories on the soap opera phenomenon PMC has created. One woman from the Southern Region of Ethiopia wrote: "I have five children and all of them are girls. My husband, however, insisted that I continue to bear children for him. As you know, bringing up one child is a big problem nowadays, let alone five children. In the Yeken Kignit drama, I heard how a couple ought to discuss such matters and that there are medicines to control childbirth. I invited my husband to listen to your program and repeatedly talked to him 
about family planning. After that, we agreed that henceforth we would have no more children and we would do our best to give proper care to those we have. Based on the advice you gave us in the radio drama, I went to the nearby clinic and received counseling services. Now I am using birth control. Your program, therefore, has benefited my husband and me and the family. There are many families who face the same problem. I think that your program would be helpful to them and should be continued" (Negussie, 2008).

In 2005 , the two authors of this chapter were together in the city of Gondar, the capital of Ethiopia from 1632 to 1855 . We were approached by a group of young boys seeking funding for their football team. Dr. Negussie asked them if they knew who Ryerson was. When they said they did not, he told them Ryerson was the global president of Population Media Center. Wide eyed, one of them asked Ryerson, "Please tell us, what happens to Damtew?" Ryerson responded, "You will just have to stay tuned to find out."

\section{Lessons Learned and Best Practices}

Traveling by car from the northwestern Ethiopian town of Bahir Dar, the capital city of Amhara Regional State, for 90 minutes one reaches the small town of Awra Amba, a farming village of 500 residents with a weaving mill. The founder of that town, Mr. Zumra, a man in his late $60 \mathrm{~s}$, has been there for nearly 40 years. Mr. Zumra stipulates that others may live in the village on the condition that they agree to absolute gender equality and absolute non-violence and implement those principles in their daily lives. At first, men from neighboring villages objected to this requirement, saying they owned their wives, so they had the right to beat them. Mr. Zumra held his ground and only admitted people who agreed to the principles.

Since Awra Amba's founding, men and women have done the housework together, plowed the fields together, and worked in the weaving mill together. Today, the town is thriving. Almost all high school graduates attend university in Addis Ababa. The townspeople are comfortable financially, and the town is even giving financial aid to neighboring villages. During our time in the village, we met many residents. All seem happy with their lives.

Awra Amba demonstrates that gender equality and non-violence are not only human rights imperatives. They are also key elements in economic welfare and human happiness. UN Women in Ethiopia, the 
organization that informed the authors of the story of Awra Amba, sees the benefit of the town serving as a role model for the entire nationindeed, the entire world.

But most people in Ethiopia have never heard of Awra Amba or of Mr. Zumra. There is a huge chasm in communications between UN offices in Addis Ababa and the living rooms of people throughout the nation. And outside of Ethiopia, very few know of Mr. Zumra's bold experiment.

An infrastructure exists to deliver Mr. Zumra's success story to the population of Ethiopia. His story is but one of many that exist in that country. Thanks to the work of the PMC, his and other culturally relevant stories can be shared, populations can be positively influenced, and changes for the betterment of society can be made.

PMC knows from its experiences in Ethiopia that meaningful changes in the attitude and behavior of people can be obtained when the issues under consideration have the support of influential people in the community. In Ethiopia, religious and community leaders like Mr. Zumra have unique positions through which they can influence people and impose sanctions in matters that directly or indirectly affect the wellbeing of community members. Capacity building and awareness creation on harmful traditional practices or, in the case of Mr. Zumra, innovative and new ways of thinking, are indispensable steps toward social change.

Entertainment-education is a proven tool to capture large audiences and move them to adopt healthful behaviors. It is most effective when it is used to role model positive behaviors and show positive consequences, rather than telling the audience what to do. Lecturing risks losing audiences and causing controversy. Use of a methodology like the one created by Miguel Sabido that is based on sound social science theory and evidence of effectiveness is key to having an impact.

How can communicators decide what behaviors to promote? Certainly, public health experts are useful advisors to creative writing teams. But working in many countries, it is important to have the values of any program based on official policies. PMC uses UN agreements to which the host country is a signatory and policies and laws of the host country if they do not counter UN agreements or human rights accords. This prevents anyone from claiming that an outside organization is trying to determine how other people should live. This also helps to ensure that in-country program designers are ethical in providing correct information to the audience, rather than trying to manipulate audiences for some unethical end. Having broad representation of expert advisors is a key element in 
ensuring program accuracy and fidelity to the cultural realities of each country.

To ensure such programs can successfully compete with other forms of entertainment programming, it is important to train creative teams in strategies for developing suspenseful storylines with cliffhangers and designing characters that people in the audience can relate to. It is also useful to design evolution of identification characters at a believable pace and as a result of key triggering events.

Equally important in design of characters, settings, and storylines is having extensive formative qualitative research underlying all aspects of the program. This implies that programs are most effective when they are culturally specific, which is why PMC does unique programs for each country or language group. It is a rare program that can be dubbed into other languages and used in other countries with any expectation of significant effects.

In Ethiopia, another principle employed by PMC is the use of its Whole Society Strategy. This makes sure that various elements of the campaign complement the serialized drama and that these are distributed via numerous media outlets in many time slots and using many different formats in order to reach the broadest swath of the population possible. All age groups, socio-economic groups, men and women, rural and urban, and other segments of the population are included, to change norms throughout the entire society.

PMC has shown that the use of effective methodologies of entertainment-education can accelerate lasting changes in social norms cost effectively compared to traditional social and health messaging. The Sabido methodology of entertainment-education started in a developing country and has mostly been used in developing countries across the globe. After 15 years of working in the developing world, Population Media Center decided to bring that methodology to the US-in a sort of reverse form of foreign aid-since the US has a serious teen pregnancy problem, not to mention other issues, and because the US exports its entertainment media all over the world. East Los High was PMC's first such US program, and it is now being seen in many other countries where it has been exported by Hulu. One can even watch it on some airlines. Meanwhile, PMC is creating new such programs in the US.

The same principles were used in Ethiopia and in the US - as well as the other countries where PMC has worked. One of those was to adapt to the local media situation and media consumption patterns. Another was to 
base the positive values modeled for the audience on the policies in the host country. Another was the involvement of expert advisors in both the cultural realities of the audience and the issues being addressed, plus service agencies to whom the audience can be referred. Another was use of extensive formative research that helps the writers capture the reality of the audience with a compelling drama. Another was to use multiple platforms and formats to get aspects of the story and the call to action across to the audience-what PMC calls the Whole Society Strategy and what Hollywood calls transmedia storytelling. Most important was use of a proven methodology that results in programs with high entertainment value to attract large audiences, so that many people in the society can benefit from the program.

\section{REFERENCES}

Barker, K., \& Sabido, M. (2005). Soap operas for social change to prevent HIV/ AIDS: A training guide for journalists and media personnel. Population Media Center. Retrieved from https://www.populationmedia.org/2005/01/06/ soap-operas-for-social-change-to-prevent-hivaids/

Cho, N. (2008). Ethiopian radio serial drama follows process to success. Population Reports, 16, 6-7.

Nariman, H. N. (1993). Soap operas for social change: Toward a methodology for entertainment-education television. Praeger Publishers.

Negussie, T. (2008, March-April). Hearing is believing. Communication World Magazine, pp. 33-36.

- (2017). Innovative media and communication strategy for development: Ethiopia's experience. Rehobot Printers.

Ryerson, W. N., \& Negussie, T. (2004). Organizing a comprehensive national plan for entertainment-education in Ethiopia. In A. Singhal, M. J. Cody, E. M. Rogers, \& M. Sabido (Eds.), Entertainment-education and social change: History, research, and practice (pp. 177-190). Routledge.

Sabido, M. (1982). Handbook for reinforcing social valuesthrough day-time T.V. serials. Televisa Communications Research Department.

Sabido, M. (2004). The origins of entertainment-education. In A. Singhal, M. J. Cody, E. M. Rogers, \& M. Sabido (Eds.), Entertainment-education and social change: History, research, and practice (pp. 61-74). Routledge.

Wang, H., \& Singhal, A. (2016). East Los High: Transmedia edutainment to promote the sexual and reproductive health of young Latina/o Americans. American Journal of Public Health, 106(6), 1002-1010. 
Open Access This chapter is licensed under the terms of the Creative Commons Attribution-NonCommercial-NoDerivatives 4.0 International License (http:// creativecommons.org/licenses/by-nc-nd/4.0/), which permits any noncommercial use, sharing, distribution and reproduction in any medium or format, as long as you give appropriate credit to the original author(s) and the source, provide a link to the Creative Commons licence and indicate if you modified the licensed material. You do not have permission under this licence to share adapted material derived from this chapter or parts of it.

The images or other third party material in this chapter are included in the chapter's Creative Commons licence, unless indicated otherwise in a credit line to the material. If material is not included in the chapter's Creative Commons licence and your intended use is not permitted by statutory regulation or exceeds the permitted use, you will need to obtain permission directly from the copyright holder. 